\title{
Hegemonia, Cultura e Educação para onde caminhamos?
}

\author{
Hegemony, Culture and Education where we walk? \\ Hégémonie, culture et éducation pour oú de marche?
}

\author{
Nilton Ferreira Bittencourt Junior ${ }^{1}$ \\ Universidade Federal do Piauí
}

\begin{abstract}
Resumo: Neste artigo buscamos a representação da escolarização/educação como mecanismo determinante na formação da cultura moderna. E como no século XXI este mecanismo apresenta indícios de ser desarticulado e substituído pelas mídias eletrônicas. Analisamos desde o processo de escolarização em massa, a partir do século XVI até os dias de hoje. Nesta análise utilizamos o conceito hegemonia do filósofo Italiano Antônio Gramsci e sua relação com o processo educativo - a pedagogia e a cultura. Neste jogo social, a escolarização em massa sofreu mutações, dentro do princípio experimental iluminista. Inicialmente com a ingênua missão de igualar seres humanos, mas tomada pela nova classe dominante, a burguesia, ser torna seu instrumento de ampliação de lucros e controle social. De libertadora das trevas da ignorância para a alienadora formação de descartáveis máquinas humanas.
\end{abstract}

Palavras-Chave: Hegemonia. Escolarização. Cultural.

Abstract: This paper sought the presentation of schooling/education as a determining mechanism in the formation of modern culture. And how in the twenty-first century this mechanism shows signs, intentionally by the ruling classes, of being disarticulation by television media and social networks. We analyzed the process of mass schooling, begin in the 16th century until the present day. This analysis uses the hegemonic concept of the Italian philosopher Antonio Gramsci and his relationship with the educational process - pedagogy and a culture. In this social game, mass schooling underwent mutations, within the experimental enlightenment principle. Initially with the naive mission of equating human beings, but taken over by the new ruling class, the bourgeoisie, becoming its instrument of expansion of profits and social control. From freedom of the darkness of ignorance to the alienating formation of disposable human machines.

Keywords: Hegemony. Schooling. Cultural.

Résumé: Dans cet article, nous cherchons la représentation de la scolarisation / éducation en tant que mécanisme déterminant dans la formation de la culture moderne. Et comme au XXIe siècle, ce mécanisme présent des signes de désarticulation et de remplacement pour les moyens électroniques. Nous avons analysé le processus de scolarisation en masse, à partir du 16ème siècle jusqu'à nos jours. Dans cette analyse, nous avons utilisé le concept d'hégémonie du philosophe italien. Antônio Gramsci et ses relations avec le processus éducatif - pédagogie et culture. Dans ce jeu social, la scolarisation de la masse subie des mutations, dans le cadre du

\footnotetext{
1 Doutorando em Educação (PPGED) Universidade Federal de Uberlândia (UFU). Mestre em Educação Tecnológica (PPGE/CEFET/ MG). Pedagogo (FaE) pela Universidade Federal de Minas Gerais (UFMG). Professor do Curso de Pedagogia no Campus Senador Helvídio Nunes de Barros da Universidade Federal do Piauí (UFPI).E-mail: niltonbittencourt@ufpi.edu.br,niltonbittencourt@gmail.com
} 
principe expérimental de l'éclairage. Initiales avec la mission naïve d'égaler les étres humains, plus de reprise pour la nouvelle classe dirigeante, la bourgeoisie, elle devient des instruments d'expansion des bénéfices et de contrôle social. Aux débuts, De libérer les ténèbres de l'ignorance, à aliénante formation de machines humaines jetables.

Mots-clés: Hégémonie. La scolarisation. La culture.

\section{Escolarização e cultura.}

Em meados do século XIX e início do século XX, o conceito de cultura sustentado pelo pressuposto evolucionista foi refutado. Um dos expoentes desta nova forma de análise antropológica, Franz Boas propõe o método histórico de pluralizar a cultura ao partir de um "relativismo cultural", diversificando o conceito para a variação dos modos de vida. Já no século XX, Clifford Geertz (1926-2006) com a antropologia interpretativa, dá uma nova dinâmica ao conceito de cultura. Para ele, a Cultura funciona como teia de significados (semiótica) que é própria de cada agrupamento de seres humanos. A cultura é a própria condição de existência dos seres humanos, ocorre na mediação das relações dos indivíduos entre si, na produção de sentidos e significados e produto das ações por um processo contínuo, através do qual, os indivíduos dão sentido à suas ações. (GEERTZ, 1989). Este conceito contribui para entendermos as questões estruturais da sociedade nas diversas épocas e realidades contextuais e, sobretudo, das diferenças e transformações que vem ocorrendo na pós-modernidade.

Aqui cabe a análise da escolarização no processo de criação das teias de significado e sua consequência quando se torna massificada.

A educação é um processo de transmissão de conhecimento determinante na formação cultural de um povo. O modo de aprender ou instituir o processo educativo sempre esteve presente nas sociedades humanas. A sistematização do processo educativo foi sendo aprimorada pela observação e em íntima relação com a prática educativa. Desenvolveram-se teorias da educação, ou pedagogias que marcaram épocas e civilizações, como a Paideia Grega, A escola de Alexandria, A educação Romana e as escolas clericais da Idade Média. A educação, enquanto escolarização, sempre esteve atrelada a condições hegemônicas.

Consideramos aqui a escolarização como "o processo e a paulatina produção de referências sociais tendo a escola ou a forma escolar de socialização e transmissão do conhecimento, como eixo articulador de seus sentidos e significados”. (FARIA FILHO, 2003, 
p. 522) A escolarização é sistemática e tem como alvo a formação do aluno, não um sujeito, mas uma classe ou geração de sujeitos. A massificação da escolarização surge principalmente decorrente do movimento da Reforma Protestante. Ao traduzir a bíblia e promulgar a necessidade de leitura e interpretação das escrituras sagradas, substituindo a transmissão oral das interpretações destas escrituras para a população em geral, tradicionalmente utilizadas pela Religião Católica, os reformadores transformaram a alfabetização em condição de fé. A Igreja Católica inicialmente foi contrária à instrução universalizante, mas assumindo a importância da instrução no campo de adesão doutrinaria institui a contra reforma e passa a escolarizar os gentios. Na disputa pela hegemonia religiosa, sobressaem a necessidade de massificação da educação/alfabetização. Os catecismos surgem como os primeiros manuais escolares modernos. (MARCÍLIO, 2005); (SAVIANI, 2007)

No pensamento de Antônio Gramsci, "hegemonia é o conjunto das funções de domínio e direção exercido por uma classe social dominante, no decurso de um período histórico, sobre outra classe social e até sobre o conjunto da sociedade.” (MOCHCOVITSCH, 1992, p. 20). E é composta por duas funções: de domínio - uso da força, processo coercitivo; e de direção intelectual e moral - promove adesão por meios ideológicos, persuasão. No mundo moderno a escolarização está fortemente vinculada à construção/manutenção de hegemonias. É a teoria da educação - Pedagogia - que orienta a escolarização, que será determinante sobre a desarticulação-rearticulação da hegemonia de uma classe/grupos sociais sobre outros. O triangulo Cultura - Teia de significados semióticos; educação - Teoria educacional ou pedagogia e hegemonia são inseparáveis. Ou seja, a educação sempre ocupou espaço desarticulação-rearticulação da hegemonia de grupos sociais, tomando espaço ocupado pela mais determinante, a dominação física sobre as massas. Por muito tempo a educação formal era privilégio dos grupos dominantes em cada sociedade. Com a massificação da educação, elementos subjetivos de poder (leitura e escrita) vão sendo incorporados por grande parte da população, proporcionando entendimento de mundo e de sociedade. A escola amplia seu espaço e importância para a garantia hegemônica, por tecer a teia de significações (ressignificações) que determina a cultura. A educação se torna a pacificadora, em busca da vida racional e produtiva.

Sempre entre a massa da população houve aqueles que se destacam nas interpretações ou tem sua vida dedicada a este trabalho. Seja de forma espontânea (interna) ou por formação (externa), há aqueles que conseguem organizar e colimar a diversidade de caminhos interpretativos em uma direção. E com a massificação da educação, essa diversificação de visões 
de mundo ganha espaço para além do campo religioso. Após Gutemberg e a imprensa, a difusão das 'letras' faz crescer o conhecimento em vários setores. A ideologia aristocrática começa a sofrer abalos, a força da razão tem seu impacto na estrutura social, devido a uma nova classe que após assumir a dominação econômica da sociedade, reivindica poderes sob o Estado para se impor enquanto classe hegemônica.

Com a hegemonia rearticulada, sob a égide da ideologia burguês industrial, a reestruturação social passa pela ampliação da massificação da educação. Seja por uma ideologia estruturante de superação da ordem anterior - igualdade de direitos e cidadania; seja por necessidade de controle e direção para a nova ordem vigente - formação do homem cosmopolita. As luzes da razão contra as trevas da ignorância. A ampliação da visão de mundo das massas, tirando-as do "senso comum" é necessária para as novas formas de trabalho, novas formas de organização demográfica, enfim nova forma de vida. A crescente histórica do processo de escolarização das massas pode ser analisado dentro do interesse de formação/ressignificação de cultura que necessitava. A socialização e educação, tarefa primária da família que fazem de seus filhos um novo membro da sociedade, com a modernidade, passa a ser também função do Estado, institucionalizado pela escola.

Os pensadores como Kant, acreditavam que através da educação o homem supera o seu ser natural, passando a fazer uso da razão, adquirindo autocontrole e formando o caráter desenvolvido na educação moral. A escola deve ensinar as normas sociais que possibilitam a coesão social e a sobrevivência da sociedade. Para Durkheim (1984) a escola é o locus da socialização. Toda sociedade deve trabalhar pela educação dos seus membros, para criar uma comunhão de ideias e sentimentos entre eles, função essencial para transmitir a herança cultural em que todos são herdeiros. Seja no ordenamento de uma sociedade - para aqueles que se encontram fora do processo civilizatório, ou para a perpetuação da sociedade civilizada, a escola é o processo que a sociedade, ao longo dos tempos, tem assegurado sua reprodução, vinculando uma geração a outra e guardando uma certa fisionomia intelectual e moral. Durkheim afirma que a escola passa a ser a instituição central na formação do caráter da criança, ficando a família secundária no processo devido sua condição de foco nas relações privadas e afetivas. A escola na modernidade deve fazer a integração dos novos membros, na medida em que estes internalizam o conjunto de ideias, sentimentos, formas de ver e sentir que definem uma dada sociedade, além, da função diferenciação na preparação dos indivíduos para ocuparem diferentes posições no mundo do trabalho. Neste processo o professor tem a 
responsabilidade de inculcar na criança os valores hegemônicos da sociedade e de transformála no ser social necessário à manutenção da sociedade.

\section{Os três estágios da escolarização em massa para a hegemonia burguesa.}

Em momento e interesse diverso do religioso, a escolarização em massa pode ser vista em situações de processos imigratórios e migratórios, que ocorreram em grande escala nos séculos XIX e XX principalmente com a aceleração do desenvolvimento dos processos produtivos nos grandes centros urbanos. Ou seja, houve o predomínio de duas teorias educacionais neste período do século XVI ao fim do século XIX. A Pedagogia Tradicional Religiosa e a Pedagogia Tradicional Laica, sendo que no início do século XX já era forte a teoria Educacional Nova ou Pedagogia Progressista. Estas últimas de orientação iluminista laica. (SAVIANI, 2007)

A transição de hegemonia de uma teoria pedagógica para outra não determina o desaparecimento da outra, mas é exatamente a mudança de uma teoria para outra que começa a ser evidenciada como direcionamento do que se quer na sociedade enquanto cultura. A cultura, como teia de significados vai muito além do que ocorre na escola. Mas a escola é o elemento catalizador capaz de manter ou alterar a cultura, seja pela produção/reprodução ideológica, seja pela produção de aparatos tecnológicos que 'reinventam' o 'ser humano'. Quando falamos de estágios, falamos de processo que se sobrepõe, que vão sendo paulatinamente transformados perpassando gerações. Assim datas e épocas são colocadas como referência processual/gestacional, não como marcos deliberados de grupos sociais.

Este processo de escolarização universal na segunda metade do século XIX e princípio do século XX, que consideramos um primeiro estágio de manutenção da hegemonia liberal burguesa. Aqui a referência é a Europa, ou escola ocidental. Estes estágios se repetem conforme a expansão deste modelo. A escola ainda era vista pela população em geral como locus de erudição destinado às classes altas. Assim para o novo modo de produção deveria ser atrativo e com resultados visíveis de elevação cultural nas massas. Há a diferenciação da escolarização em massa anterior pelo seu conteúdo, que focava na racionalização, no domínio das técnicas de transformação da natureza em detrimento ao conhecimento das escrituras bíblicas. Estas escolas formavam para o trabalho moderno, diferenciado do processo de produção até então existente, rompimento de uma ideologia patriarcal para a ideologia industrial. Por isso era necessário à escolarização em massa uma fundamentação teórico 
motivacional, para a população em geral, de formação libertária, de elevação real da cultura geral. Ensinava-se um novo modo de vida, com controle de horários, de comportamentos com programas educacionais higienistas e normalizadores. Mais que um novo ofício, dava oportunidade de bons empregos e elevação de classe social, pois também ensina modos de vida e de ampliação de direitos civis - consciência de sí, e forma de convivência e mobilidade social - consciência de classe. Este último aspecto muitas vezes visto como efeito colateral da escolarização das massas, pois gera consciência política e reinvindicações. Mas prevalecem, pois, são aspectos necessários para atrair as massas para dentro da sala de aula, dando consciência de pertencimento. O controle sobre os comportamentos (controle de reinvindicações não desejáveis) era realizado de forma externa, pela força.

Quando o processo de escolarização já se encontra consolidado nas massas, como representação semiótica de 'bom emprego e ascensão social', amplia-se a função de reprodução ideológica e manutenção da hegemonia da classe burguesa. É um segundo estágio. Há uma sutil mudança na escolarização das massas, com a ampliação do controle externo - da vida moral, e da seleção (exclusão) de não conformidades. O desenvolvimento de novas formas de produção, onde a força física é cada vez menos utilizada e a formação de seguimentos destinado ao trabalho na organização e administração dos setores produtivos se tornam complexos e cada vez mais fragmentados. Só a escolarização não é mais garantia de empregos com salários dignos. Se no período anterior a escolarização massificada tinha como função a integração/socialização de indivíduos, nesta fase, serve principalmente à manutenção da hegemonia burguesa e na exclusão de não conformidades, sejam estas formas de pensamentos diferentes de sua visão de mundo, seja na marginalização daqueles que resistem a inculcação desta ideologia. É um período de inculcação da ideologia da meritocracia ${ }^{2}$, e luta contra o efeito colateral $^{3}$ do processo de escolarização das massas. Gramsci aponta este efeito colateral da escolarização:

Para Gramsci, a elevação cultural das massas para adequá-las à modernização e ao crescimento das forças produtivas da sociedade capitalista tem repercussões contraditórias: o acesso aos códigos dominantes dos quais a alfabetização é o primeiro passo, o conhecimento de direitos e deveres, e a capacidade de exigi-los podem educar também para a transformação da ordem e não apenas para o conformismo e adesão. (MOCHCOVITCH, 1992, p 64-65)

\footnotetext{
${ }^{2}$ Existe vasta pesquisa que apontam para as falhas da visão meritocrática escolar como determinante na seleção de pessoas para cargos na hierarquia social. O fator de origem social é flagrantemente maior nesta determinação. Para aprofundar veja CARNNOY, Education as Cultural Imperilism - 1972, pág 332.

${ }^{3}$ Já citado anteriormente, e conceituado neste momento.
} 
É após a adesão das massas no processo de escolarização ( $1^{\circ}$ estágio) que a ampliação e o controle sobre estas escolas deve aumentar. Os movimentos de seleção/exclusão devem ser constantemente renovados, aumentando a eficiência de filtros que possam capturar movimentos de libertação ideológica que a escola pode proporcionar. O controle das teorias educacionais - Pedagogias e seus pensadores ganha destaque. No ponto de estagnação, de crise no sistema cultural imposto pela hegemonia industrial burguesa, que as massas começam a perceber sua condição e começa a emergir formas de resistência e luta, próprias desta classe. Daí a necessidade de rearticulação reacionária. Num ato emergencial, transformam reivindicações antigas das massas, em causa dos problemas ${ }^{4}$, apontando os princípios burgueses como soluções. Ou seja, como um pai que lembra a seu filho sobre os conselhos dados e não seguidos. Apelam para um bom senso, que busca simplificar o contexto e contrapor o entendimento de lideranças populares. Se não funcionar, apelam para a força (Estado legal). A importância da meritocracia é no aspecto psicológico de dominação. Esta como justificativa de hierarquização toma o aspecto de uma estrutura de justiça social, classificando os alunos por méritos e capacidades escolares, e responsabilizando o indivíduo por seu próprio fracasso. Para Carnnoy confiar a educação a alocação de papeis sociais é hierarquizar as relações escolares entre pares, ou seja, filtrar e valorizar crianças com atitudes burguesas. Outra forma de superação do dilema da expansão de escolaridade a todas as classes foi resolvido criando um sistema educacional 'dual' com escolas preparatórias às carreiras universitárias para um seleto grupo e escolas técnico vocacionais para a maioria. (CARNNOY, 1972). Exemplos modelo francês, ainda atual, e o brasileiro até a década de 1970, quando deixa de existir legalmente e passa vigorar veladamente com sistemas público e particular de ensino.

As distinções de classe no mundo são determinadas pelas relações sociais - teias de significação. A escolarização em massa no seu primeiro estágio buscou equalizar as diferenças e dar uma unidade de cidadania que fosse comum a uma diversidade de sujeitos originários das mais diferentes culturas (teias de significação). No segundo estágio se torna fundamental a consolidação da nova estrutura burguesa e o reforço de manutenção da hegemonia. Justificativas internalizadas como natural da diferença de classes e grupos sociais, como a questão étnica, não se sustenta como antes. Mesmo porque são consideradas ultrapassadas para o mundo iluminado.

\footnotetext{
${ }^{4}$ Como exemplo a teoria Malthusiana ainda hoje é usada para justificar que é impossível todos terem acesso à tudo que se produz e que a desigualdade de classes é natural e harmônica. Outro exemplo que ainda insiste é a questão étnica ainda é aceita como fator natural que justifica a eficiência social de uma classe sobre outras.
} 
A teoria da meritocracia ganha importância neste momento e é a filosofia que passa a ser inculcada no senso comum. A meritocracia sempre fez parte da atividade de escolarização, idealizada como forma justa, mas desvirtuada para manutenção de estruturas de classe, ao se basear em critérios morais de se julgar o mérito. Quem detinha mérito era aquele mais ajustado ao sistema capitalista de produção. Para Gramsci, a distinção entre trabalhador intelectual e trabalhador braçal não está no "critério intrínseco às atividades intelectuais," mas "no conjunto do sistema de relações no qual estas atividades se encontram, no conjunto geral das relações sociais" (GRAMSCI, 1979, pp 6-7).

A determinação de um intelectual na sociedade se faz pela direção de sua atividade profissional. A capacidade intelectual é inerente a cada ser humano. Na relação do trabalho os dirigentes usam a capacidade intelectual e o operário "terá que se abster de usá-la", sendo obediente a direção dada. Fora do trabalho, ele exercerá livremente sua intelectualidade.

O problema da criação de uma nova camada intelectual, portanto, consiste em elaborar criticamente a atividade intelectual que existe em cada um em determinado grau de desenvolvimento, modificando sua relação com o esforço muscular-nervoso no sentido de um novo equilíbrio e conseguindose que o próprio esforço muscular-nervoso, enquanto elemento de uma atividade prática geral, que inova continuamente o mundo físico e social, torne-se o fundamento de uma nova e integral concepção de mundo. (GRAMSCI, 1979, p. 8)

É este o dilema da escolarização e elevação cultural das massas. Sem a devida atenção à critérios racionalizados de seleção meritocrática, seja de forma intencional ou não, a escola desvirtua sua função organizadora. Sem o devido cuidado, os critérios de méritos ligados a fatores de moral tradicional sobrepõe-se aos critérios de fatores intelectuais, favorecendo a reprodução de estruturas de classes pré existentes, forma reprodutora de um sistema de valores sociais já existentes e hegemônicos. De equalizadora e locus de inserção social, passa a ampliar sua função excludente e conformista. Ao elevar o conhecimento das massas, aqueles que se destacam e não veem suas oportunidades aparecerem, denunciam as falhas do sistema. E fazem coro aos que resistem ao processo de escolarização/aculturação, ou ressignificação cultural. Gramsci já apontava o papel social da escola na formação de intelectuais desde o mundo medieval. Dentre eles os teóricos do Iluminismo que transformaram a hegemonia aristocrática. Com a massificação, a necessidade do controle da educação se torna cada vez maior. A escola, nos planos supraestruturais, locus da formação social, é que garantirá a hegemonia do grupo dominante sobre toda a sociedade, reproduzindo sua ideologia e repelindo inconformados. Se não pelo consenso espontâneo, será pelo disciplinamento dos resistentes, 
através do aspecto psicológico de auto responsabilização pelo fracasso e por fim, usando-se a questão legal. A meritocracia desta forma, mantem elementos da educação clássica, aristocrática e deve ser internalizada como princípio de legitimação espontânea, e cumprir seu propósito de justificativa para as desigualdades de classe, velando-se os privilégios de acesso a conhecimentos herdados, que a origem de classe garantirá a seus descendentes.

A divisão fundamental da escola em clássica e profissional era um esquema racional: a escola profissional destinava-se às classes instrumentais, ao passo que a clássica destinava-se às classes dominantes e aos intelectuais. $\mathrm{O}$ desenvolvimento da base industrial, tanto na cidade como no campo, provocava uma crescente necessidade do novo tipo de intelectual urbano: desenvolveu-se, ao lado da escola clássica, a escola técnica (profissional mas não manual), o que colocou em discussão o próprio princípio da orientação concreta de cultura geral, da orientação humanista da cultura geral fundada sobre a tradição greco-romana. Esta orientação, uma vez posta em discussão, foi destruída, pode-se dizer, já que sua capacidade formativa era em grande parte baseada sobreo prestígio geral e tradicionalmente indiscutido de uma determinada forma de civilização. (GRAMSCI, 1979, p. 118)

Para melhorar o controle sobre as massas que passam a reivindicar escolarização, era necessário a abolição da escola clássica erudita. Isso aumentaria a ruptura com a velha ordem, minimizando o impactos das visões de desigualdade que emergiam, dando a ideia de 'projeto em implantação’ e serviu de prerrogativa para uma resposta à crítica de escola aristocrática e valorização da meritocracia, pois uma escola igualitária para todos é uma escola democrática e justa, onde os mais capazes intelectualmente irão dirigir a sociedade ${ }^{5}$. Inicialmente este modelo de escola foi importante para possibilitar a mobilidade social, fato que ocorreu em maior intensidade no princípio, reforçando a instituição escolar como necessária em camadas populacionais que resistiam em frequentá-la. Com sua consolidação social e saturação de cidadãos escolarizados, emergiram outros aspectos sociais que influenciam no sucesso ou fracasso na mobilidade social. "A formação em massa estandartizou os indivíduos, na qualificação intelectual e na psicologia, determinando os mesmos fenômenos que ocorrem em todas as outras massa estandartizadas: Concorrência, desemprego, superprodução escolar, emigração, etc.” (GRAMSCI, 1979, p. 12). A meritocracia deveria trazer o efeito de reordenamento. Mas mantendo alguns elementos morais da escola aristocrática, seja de forma intencional ou como resquícios dos hábitos escolares na transição de gerações.

\footnotetext{
${ }^{5}$ Um exemplo deste processo foi a promulgação da primeira LDB - Lei de Diretrizes e Bases da educação Brasileira - Lei 4.024 em 1961, que começou com os debates sociais e políticos 1948, levando 13 anos para ser concluída, devido ao conservadorismo de se manter o aspecto formativo humano clássico da educação básica.
} 
A escola para o homem moderno tinha que ser pensada de forma a minimizar os efeitos colaterais, como dito acima, na mudança tanto na forma de produção quanto de vida. Acirrouse o controle moral e os princípios meritocráticos na sociedade em geral. A psicometria é o instrumento marcante que dava cientificidade à meritocracia neste estágio. Os testes de QI Quoeficiente de Inteligência - são introduzidos para selecionar objetivamente pessoas adequando-as aos cargos dentro da hierarquia social, com base na inteligência ou desempenho escolar. Carnnoy, com base nos trabalhos de Bowles e Gintis ${ }^{6}$, afirma que a origem social de humanos adultos é bem mais determinante que as diferenças de QI entre estas pessoas. E que os testes objetivos têm sido utilizados, como refinamento da teoria meritocrática, para legitimar hierarquias econômicas e de classe social.

Na segunda metade do século XX, por meio de pesquisas na área da sociologia escolar, ficou explicita a questão cultural, evidenciando o currículo escolar na base de determinação do fracasso ou sucesso dos alunos conforme a classe social/cultural a que pertencem. Esta constatação gerou novo ponto para crise e reivindicações de uma escola que cumpra os princípios de inserção e equidade social. A meritocracia da forma que foi implementada sofria abalos conceituais. Era necessário a ressignificação destas teorias para manutenção do papel reprodutor da escola como forma de garantir a hegemonia de grupo.

A teoria educacional tecnicista ou Pedagogia Tecnicista foi a característica deste modelo educacional. A escola assume uma função de formar trabalhadores, ficando reduzida a serventia do mercado econômico. (ARAPIRACA, 1982). É o momento em que a escola passa ser vista apenas sob o viés técnico, abrindo mão de formar cidadãos. Princípios de administração empresarial são incorporados e a moral tradicional é substituída pela moral empresarial.

A pedagogia tecnicista, teoria educacional a ser implementada deveria garantir a reprodução do modelo estrutural capitalista, combater a ideologia Soviética (Comunismo) ${ }^{7}$ e eliminar os efeitos colaterais da educação. O modelo de formação idealizado era o de um

\footnotetext{
${ }^{6}$ Segundo estes autores “[ ...] Enquanto o status econômico tende a se parecer muito com o dos pais, apenas uma pequena parte dessa associação pode ser atribuída a diferenças de classe social nos recursos genéticos mesmo aceitando as estimativas de hereditariedade de Jensen. Assim, uma perfeita equalização do QI entre as classes sociais reduziria a transmissão intergeracional do status econômico por uma quantia insignificante." (BWLES \& GINTIS, apud CARNNOY, 1977, pág 332)

${ }^{7}$ Ironicamente, um dos livros base na determinação de qual modelo de educação a ser desenvolvida no Brasil pela USAID, nas décadas de 1960-1970, optou-se pela visão do movimento empresarialista nos EUA, que conforme seus principais pensadores - Clark Kerr, John Dunlop, Frederick H. Harbinson e Charles A. Mayers, o melhor modelo de educação seria o empregado na China e União Soviética, países considerados de modelo comunista a ser combatido. Para mais informações ver Industrialism and Industrial Man, traduzido no Brasil como Industrialismo e Sociedade Industrial, de autoria dos 4 pesquisadores citados. (editora Fundo de Cultura, 1960)
} 
intelectual que fosse capaz de se adequar ao sistema de produção, em constante mutação dadas os avanços tecnológicos. Essa formação deveria também inculcar princípios da competição e individualismo, próprios do mercado capitalista. Isso evitaria a formação de consciência de classe formando técnicos com postura política individualizada, pois o conhecimento é colocado como produto a ser vendido. O cidadão passa a ser contribuinte.

A meritocracia toma nova forma, conforme os interesses individuais e ambição pessoal, como formas de escolhas e liberdade individual. Tudo dentro da moral empresarial, ficando a cargo do indivíduo capitalizar-se de conhecimento para ter mais valor no mercado, aumentando a competitividade, o lucro. Aqueles que não o fazem, não merecem 'lugar ao sol'. A forma de equalização social, colocada na educação universal começa a ser racionalizada para a criação de necessidades da formação para produção e consumo. Reforça-se a ideia que a educação é mercadoria ${ }^{8}$. "O enfraquecimento da escola pública, paralelo ao crescimento do sistema privado, deu-se ao mesmo tempo em que a socialização deslocou-se da escola para a mídia, a publicidade e o consumo.” (MÉZÀROS, 2008, p. 16) A mídia televisiva é uma possibilidade de educação e controle na produção de desejos e também na formação de uma “intelectualidade" com leituras de mundo prontas capazes de auxiliar no processo educativo e principalmente, proporcionar um lazer controlado e individualizado. "O negócio se organiza como uma grande máquina capitalista, que utiliza os processos tecnológicos mais avançados, voltada para a produção da mercadoria entretenimento, que consumida, dá suporte aos anúncios das grandes empresas”. (MELLO \& NOVAIS, 1998, p. 638). A mídia, além de dar a falsa sensação de pertencimento de grupo, paralelamente à escola, disputa espaço na formação de consciências. Professores são confrontados com informações de programas televisivos. “Mas professor, passou no Fantástico9!". Aparatos tecnológicos confere o status moderno e atualizado.

Paralelo a implantação da pedagogia tecnicista, criou-se uma indústria cultural televisiva, fonográfica e editorial consumida pela nova classe média. Way of life americano para o mundo. Além de entretenimento esta mídia favoreceu a institucionalização de intelectuais e

\footnotetext{
${ }^{8}$ Mesmo após à promulgação da Lei LDB -4.024/1961, o Brasil ainda continuou a ter uma educação básica dualista, por resistência de setores conservadores da sociedade brasileira. Em 1971, com a promulgação da Lei 5.692, de reforma da educação básica no Brasil, que pôs fim a este dualismo, universalizando a educação básica numa única forma - Formação vocacional no $1^{\circ}$ Grau e técnica no $2^{\circ}$ Grau. Após esta lei houve a expansão da rede pública e também privada, e por "melindres" legais, o dualismo passou a ser velado. Para mais informações ver BITTENCOURT, N F - AMERICANISMO E EDUCAÇÃO PARA O TRABALHO NO BRASIL: UM ESTUDO SOBRE OS GINÁSIOS POLIVALENTES (1971-1974) dissertação de mestrado. Disponível em http://www.posgraduacao.cefetmg.br/cefet-mg-ppget/index.php/pt/dissertacoes capítulo 2; 2013

${ }^{9}$ Fantástico é um tradicional programa de TV aberta no Brasil
} 
artistas. O intelectual libertário, militante, engajado, altruísta, atormentado com sua condição privilegiada numa sociedade subdesenvolvida, vai cedendo lugar ao intelectual profissional, resignado e passivo, que observa o mundo, mas não o contradiz, apenas se adapta à sua condição de intelectual acadêmico, preocupado com sua carreira profissional. (RIDENTI, 2012).

A educação nos moldes da pedagogia tecnicista criou um espaço educacional individualizado e os docentes como meros técnicos a facilitar o entendimento de conteúdos prontos, além de fazer o papel coercitivo de conformação das consciências desajustadas. A educação (principalmente a educação pública) passa a ter a função de conformação com a situação de reprodução de um sistema social acabado. O mérito do não acesso aos bens culturais valorizados encontram-se no aluno, por este fazer más escolhas, como se realmente tivesse escolha. As inconformidades que surgem são resinificadas ou demonizadas ${ }^{10}$. Com a disseminação do aparato midiático, trocou-se as armas pelo "jingles” e telejornais formadores de um senso comum "intelectualizado", cheios de frases de efeito e esvaziados de conhecimento (apenas a visão de mundo de classe dominante). Reforçadores de uma filosofia histórica e apaziguadora, transformando a dominação em salvação. Toda expressão de libertação originariamente do povo é capturada para ser útil às classes dominantes, que farão a releitura midiática daquela realidade, ajustando ao que lhes favorece e demonizando as não conformidades numa generalização de que o ato de libertação plena vai contra a ordem pré estabelecida e deve ser extirpado por colocar em risco todo o progresso conquistado. A racionalidade do lucro tem por ordem eliminar a concorrência e os problemas sociais de não produtividade. Com o avanço tecnológico e midiático (redes sociais) este quadro se acentua nos dias atuais.

Uma característica central da sociedade em rede é a transformação da área da comunicação, incluindo os media. A comunicação constitui o espaço público, ou seja, o espaço cognitivo em que as mentes das pessoas recebem informação e formam os seus pontos de vista através do processamento de sinais da sociedade no seu conjunto. Por outras palavras, enquanto a comunicação interpessoal é uma relação privada, formada pelos actores da interacção, os sistemas de comunicação mediáticos criam os relacionamentos entre instituições e organizações da sociedade e as pessoas no seu conjunto, não enquanto indivíduos, mas como receptores colectivos de informação, mesmo quando a informação final é processada por cada indivíduo de acordo com as suas próprias características pessoais. É por isso que a estrutura e a dinâmica

\footnotetext{
${ }^{10}$ A rotulação de grupos dissidentes tornou arma de controle e coerção social, com a intensificação do mecanismo de patrulhamento ideológico. Por exemplo: o rótulo de "comunista" como símbolo do atraso e selvageria e mais atualmente os "Black Blocks".
} 
da comunicação social é essencial na formação da consciência e da opinião, e a base do processo de decisão política. (CASTELLS, 2004, p 23)

Se a escolarização foi o locus de criação e controle de redes de informação e conhecimento, atualmente a mídia cumpre este papel de forma mais ampla e eficiente, e sem efeitos colaterais (até o momento). Isso anuncia o fim da necessidade, para a revolução burguesa, de uma mudança radical no contexto da escolarização massificada, o fim de uma educação massificada. Da escolarização em massa só restará a contenção e conformação de interesses.

A classe burguesa está 'saturada': Não só se amplia, mas se desagrega; não só
assimila novos elementos mas desassimila uma parte de si mesma (ou pelo
menos as desassimilações são muitíssimos maiores que as assimilações). Uma
classe que não se considere capaz de assimilar toda a sociedade, e ao mesmo
tempo seja realmente capaz de exprimir este processo, leva a perfeição esta
concepção de Estado e do direito, em virtude de terem eles completado a sua
missão de terem sidos absolvidos pela sociedade civil. (CASTELLS, 2004, p
147 )

No fim, somos todos - patrões, banqueiros, funcionários, empregados - alienados de nossa condição humana. Viramos peças da estrutura social moderna.

\section{Conclusão}

É neste crescente da ação da mídia que a educação em massa vai perdendo seu poder frente a manutenção da atual hegemonia dominante. Após um período de dependência da educação em massa, a atual consolidação do processo educativa no primeiro estágio, o acirramento do controle sobre a educação e dos critérios meritocráticos no segundo e a capitalização do conhecimento, desvirtuando o foco de aprendizado para auto aprendizado, no terceiro estágio, finalmente a educação em massa começa a ser ressignificada no senso comum, como desnecessária. A mídia televisiva cumpre melhor este papel por eliminar o efeito colateral de consciência de grupo, colimando todos em uma "colmeia" de grupo, harmônica e finalística do sistema social humano. Na ânsia de ganhar mais, aumentar a produtividade, perde-se em humanidade. Retoma-se o antigo vício de superioridade, antes de sangue, agora de produção, riqueza.

Enfim, a burguesia ressignificou os modos de produção, os modos de viver em comunidade, os modos de pensar o mundo e com a mídia ressignificou o ideário coletivo e se tornou o Estado "Educador" pleno. A educação que ilumina as mentes para o progresso, 
também iluminam para a liberdade e para o conhecimento de si. Atualmente é necessário muita técnica e pouco conhecimento. Muita habilidade e pouca sabedoria. Como no romance Fahrenheit 451, de Ray Bradbury (1953), o conhecimento se torna cada vez mais perigoso, e os livros inimigos da harmonia social da modernidade.

\section{Bibliografia:}

ARAPIRACA, J. O. A USAID e a Educação Brasileira: um estudo a partir de uma abordagem crítica da teoria do capital humano. São Paulo, Autores Associados: Cortez, 1982.

CASTElls, M. A Sociedade em Rede: Do Conhecimento à Acção Política. 2004. disponível em: http://eco.imooc.uab.pt/elgg/file/download/51670 Acesso em 10/07/2018

CARNNOY, Martin Education as Cultural Imperialism. Longman Inc., New York, $3^{\text {a }}$ printing, 1977

DURKHEIM, E. Sociologia, Educação e Moral. Tradução por Evaristo Santos. Porto: Rés Editora, 1984

FARIAS FILHO, L. M. de; LOPES, E. M. T.; VEIGA, C. G. 500 anos de educação no Brasil. $3^{\mathrm{a}}$ edição. Belo Horizonte: Autêntica, 2003.

GEERTZ, C. A interpretação das culturas. Rio de Janeiro: LTC Editora, 1989.

GRAMSCI, A. Concepção dialética da história. 4. ed. Rio de Janeiro: Civilização Brasileira, 1981. 341 p. (Perspectivas do homem, v. 12). Inclui bibliografia e indice. ISBN (broch.).

MARCÍlLIO, M. L. História da Escola em São Paulo e no Brasil. São Paulo: Imprensa Oficial do Estado de São Paulo: Instituto Fernand Braudel, 2005.

MELLO, J. M. C. \& NOVAIS, F. A.. Capitalismo Tardio e Sociabilidade Moderna in: História da Vida Privada no Brasil: Contrastes da intimidade contemporânea - São Paulo: Cia das Letras, 1998. Pp.559-658.

MÉZÀROS, I. Educação para Além do Capital $2^{a}$ edição, Boitempo, SP 2008

MOCHCOVITCH, L. G. Gramsci e a Escola Ed Ática, SP, $3^{\text {a }}$ edição, 1992

RIDENTI, M. Cultura e Política: os anos 1960-1970 e sua herança. In: O tempo da ditadura: Regime militar e movimentos sociais em fins do século XX. Rio de Janeiro: Civilização

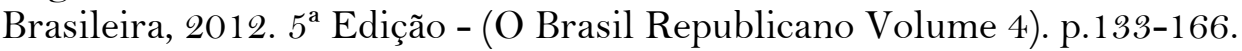

SAVIANI, D. História das idéias pedagógicas no Brasil. Campinas: Autores Associados, 2007. $473 p$ 